\title{
Prognostic Influences of Cardiac Rehabilitation in Korean Acute Myocardial Infarction Patients
}

\author{
Chul Kim, M.D., Duk You Kim, M.D., Chang Jin Moon, M.D.
}

Department of Rehabilitation Medicine, Sanggye Paik Hospital, Inje University College of Medicine, Seoul 139-707, Korea

Objective To observe the prognostic influences of the cardiac rehabilitation (CR) program in Korean acute myocardial infarction (AMI) patients during the first year after an occurrence of the disease.

Method A total of 141 AMI patients who underwent percutaneous coronary intervention (PCI) were recruited consecutively for this study and divided into the CR group and the control group. The CR group completed the phase 2 CR program in the hospital for a period of 6-8 weeks and maintained self-exercise in their community by exercise prescription for a year after AMI. We performed a prospective comparison of the patients' demographic data, high sensitive C-reactive protein (hs-CRP) level after the 4-month CR program, and the rate of recurrence (AMI, re-hospitalization, positive coronary angiogram, needed revascularization procedure, or death) between the two groups.

Results Compared to the control group $(0.33 \pm 0.48 \mathrm{mg} / \mathrm{dl})$, the hs-CRP level was lower in the CR group $(0.18 \pm 0.32$ $\mathrm{mg} / \mathrm{dl})$ after 4 months of exercise. The recurrence rate was lower $(10 \%, 7 / 69)$ in the CR group, compared to the control group $(24 \%, 17 / 72, \mathrm{p}<0.05)$. The number of disease-free days was larger in the CR group (354 \pm 38.34$)$, compared to the control group $(316 \pm 99.96, \mathrm{p}<0.05)$. In a comparison of statistical methods used for testing the equality of two survivor distributions, the CR group showed a lower recurrence rate than the control group $(\mathrm{p}<0.05)$. Conclusion Participation in the CR program designed for AMI patients who underwent PCI-induced normalization of the serum hs-CRP level and lowering of the recurrence rate by $14 \%$ during the first year.

Key Words Myocardial infarction, Rehabilitation, Event-free survival rate, hs-CRP, Recurrence rate

\section{INTRODUCTION}

Cardiovascular diseases are the third leading cause of death after cancer and are on the rise, according to the annual data of the Korean National Statistical Office in 2008. The mortality rate of circulatory system diseases is 112.3 per 100,000 members of the population. Among

Received September 2, 2010; Accepted January 4, 2011 Corresponding author: Chang Jin Moon

Department of Rehabilitation Medicine, Sanggye Paik Hospital, Inje University, 761-1, Sanggye 7-dong, Nowon-gu, Seoul 139-707, Korea Tel: 82-2-950-1134, Fax: 82-2-935-3076, E-mail: cjmoon7@gmail.com Copyright $\odot 2011$ by Korean Academy of Rehabilitation Medicine them, mortality rates of cerebrovascular, cardiovascular, and hypertensive diseases are 56.5, 43.4, and 9.6 per 100,000 , respectively. Among cardiac diseases, ischemic heart diseases show the highest rate of mortality, at 25.7. ${ }^{1}$

Cardiac rehabilitation (CR) in patients with acute myocardial infarction (AMI) ensures more efficient management of risk factors, as well as improved cardiopulmonary function, quality of life, and psychosocial function. It also reduces recurrence rate, revascularization rate, cardiovascular disease-related mortality, and the mortality rate of non-cardiovascular diseases. ${ }^{2,3}$ In addition, findings from previous studies 
support that long-term CR either delays the atherosclerosis process or reduces the intensiveness of the disease. $^{4,5}$

As atherosclerosis, which causes coronary disease, has inflammatory pathogical physiology related to endothelial injury and atheromatous plaque rupture, increase of the hs-CRP level, an inflammatory marker, is the strongest predictive factor for future cardiovascular disease.$^{6-8}$ AMI patients require systematic management of risk factors, including exercise, which can provide more integrated and efficient adjustment of high blood pressure, diabetes, atherosclerosis, and dyslipidemia. CR can ultimately result in reduced recurrence, rehospitalization, revascularization, and overall mortality rate. ${ }^{9,10}$

However, there has been no comparative study of the recurrence and mortality rate in Koreans between patients who participated in CR after an occurrence of AMI and those in the control group. Therefore, we attempted to apply the CR program to AMI patients and determine the influences of CR on recurrence, revascularization, and mortality rate throughout a oneyear period of monitoring of the control group without CR.

\section{MATERIALS AND METHODS}

\section{Subjects}

Patients at the cardiac rehabilitation clinic after PCI or coronary artery bypass graft (CABG) for AMI at the cardiovascular center of our hospital for the first time from January 2006 to December 2007 were divided into the exercise group and the control group for the study. Subjects were monitored prospectively for a period of one year. Patients with stroke, cancer, or neuromusculoskeletal symptoms that might impede CR program completion were excluded. Patients were asked to choose whether they participated in the CR or not and divided into the exercise group and the control group accordingly. Both groups maintained their medication for high blood pressure, diabetes, and dyslipidemia and were monitored in our cardiac rehabilitation clinic and cardiovascular outpatient center for more than a year after an occurrence of AMI.

\section{Methods}

Patients in the exercise group participated in an ECG monitoring exercise at the hospital according to the exercise prescription for a period of 6-8 weeks along with strict management of risk factors. Prior to the CR program, all patients in the exercise group took the symptom limited exercise test using a modified Bruce protocol. The exercise test included use of the Q4500, Model 412, and Medtrack ST 55 (Quinton Instrument Co., Boston, USA). The exercise prescription was based on the initial test result. The first exercise time consisted of a total of 50 minutes, including warm-up (10 min), exercise (30 $\mathrm{min})$, and cool-down (10 min). Intensity of exercise was adjusted on a test result basis by calculation of heart rate reserve first, followed by the increased target heart rate from $40 \%$ to $85 \%$ of the value in phases. Rate of Perceived Exertion (RPE) was maintained at 13-14 (somewhat challenging). After 6-8 weeks of the monitoring exercise program, the exercise test was taken again to suggest new exercise prescriptions with a readjusted target heart rate and RPE. Accordingly, subjects were asked to maintain a self-exercise program in the community.

On the contrary, patients in the control group underwent general training on exercise or risk factors management and were instructed to maintain their own exercise training and cardiovascular risk factors management. Patients in both the exercise group and the control group received cardiovascular medications and underwent testing for hs-CRP, the inflammatory marker, during the initial stages of AMI and additionally around 4 months after its occurrence. Subjects in the two groups were monitored for a period of one year after the occurrence of AMI and their recurrence frequencies were compared. The definition of recurrence included when the patients required hospitalization due to an occurrence of AMI or unstable angina, Coronary Angiography (CAG) with apparent angina symptoms, revascularization, such as PCI or CABG, and cardiovascular-related death or other deaths due to different causes. ${ }^{2,3,11}$

\section{Statistical analysis}

Chi-square analysis was used for comparison of gender ratio, recurrence rate, revascularization, and mortality rate between the two groups, while the t-test was applied for comparison of age and left ventricle ejection fraction (LVEF) between them. Comparison of the recurrence rate in an identity test of the survival curve in the groups used 
the Kaplan-Meier event-free survival curve. In addition, the SAS Enterprise Guide 4.1 (4.1.0.471) was used as a statistical program and level of significance was $\mathrm{p}<0.05$.

\section{RESULTS}

\section{General characteristics of the target patients}

No significant differences in general characteristics such as gender ratio and patient's age were observed between the exercise group (69) and the control group (72) ( $\mathrm{p}>0.05$, Table 1). The LVEF of the exercise group (54.53 $\pm 13.66 \%)$ before the CR program was higher than that of the control group $(50.11 \pm 12.74 \%)$; however, the difference was not statistically significant.

Table 1. Characteristics of Subjects

\begin{tabular}{lccc}
\hline & $\begin{array}{c}\text { Exercise } \\
\text { group } \\
(\mathbf{n}=69)\end{array}$ & $\begin{array}{c}\text { Control } \\
\text { group } \\
(\mathbf{n}=72)\end{array}$ & p-value \\
\hline Male/female & $49 / 20$ & $60 / 12$ & 0.08 \\
\hline Age (year) & $61.93 \pm 10.67$ & $64.49 \pm 9.31$ & 0.13 \\
\hline LVEF (\%) & $54.53 \pm 13.66$ & $50.11 \pm 12.74$ & 0.07 \\
\hline PTCA/CABG & $64 / 5$ & $66 / 6$ & 0.81 \\
\hline BP medication & $62(90 \%)$ & $68(94 \%)$ & 0.36 \\
\hline DM medication & $17(25 \%)$ & $12(17 \%)$ & 0.24 \\
\hline Statin & $60(87 \%)$ & $64(89 \%)$ & 0.70 \\
\hline
\end{tabular}

LVEF: Left ventricular ejection fraction, PTCA: Percutaneous transluminal coronary angioplasty, CABG: Coronary artery bypass graft, BP: Blood pressure, DM: Diabetes mellitus

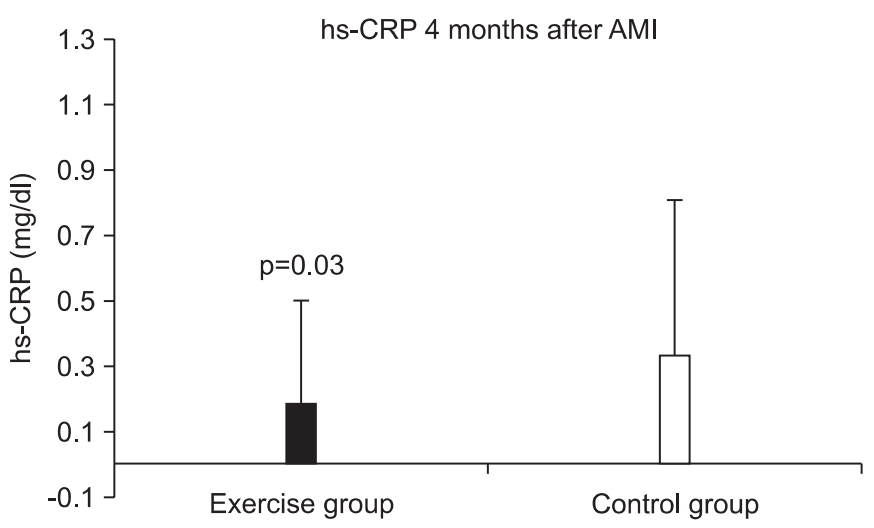

Fig. 1. Comparison of the hs-CRP level between the CR group and the control group 4 months after CR program completion.
Comparison of hs-CRP and $\mathrm{HbAlC}_{1}$ levels between the exercise group and the control group

The exercise group $(0.18 \pm 0.32 \mathrm{mg} / \mathrm{dl})$ showed a significantly lower value of hs-CRP than the control group $(0.33 \pm 0.48 \mathrm{mg} / \mathrm{dl})$ at around 4 months after an occurrence of AMI ( $<<0.05$, Fig. 1$)$. The exercise group only showed normalized hs-CRP. No noticeable differences in hs-CRP prior to exercise were observed between the exercise group $(1.74 \pm 4.02 \mathrm{mg} / \mathrm{dl})$ and the control group $(3.19 \pm 4.67$ $\mathrm{mg} / \mathrm{dl}$ ) ( $>0.05$, Table 2). Additionally, the exercise group included 2 patients (3\%) with unadjustable diabetes with an HbAlc level over 6, lower than that of the control group, which included 4 patients ( $3 \%)(p>0.05$, Table 3 ).

Recurrence rate and death rate between the exercise group and the control group for a period of one year

The recurrence rate was monitored for a period of 1 year; results showed recurrence in 7 patients $(10 \%)$ in the exercise group, and 17 patients $(24 \%)$ in the control group, indicating a significantly lower rate in the exercise group ( $\mathrm{p}<0.05)$. Among the 7 patients, 2 received CAG

Table 2. Comparison of hs-CRP Levels between the CR Group and Control Group 4 Months after CR Program Completion

\begin{tabular}{lccc}
\hline & $\begin{array}{c}\text { Exercise } \\
\text { group } \\
(\mathbf{n}=69)\end{array}$ & $\begin{array}{c}\text { Control } \\
\text { group } \\
(\mathbf{n}=72)\end{array}$ & p-value \\
\hline $\begin{array}{l}\text { Baseline hs-CRP } \\
(\mathrm{mg} / \mathrm{dl})\end{array}$ & $1.74 \pm 4.02$ & $3.19 \pm 4.67$ & 0.08 \\
$\begin{array}{l}\mathrm{h} \text { h-CRP }(\mathrm{mg} / \mathrm{dl}) \\
\begin{array}{l}4 \text { months after } \\
\text { the CR program }\end{array}\end{array}$ & $0.18 \pm 0.32$ & $0.33 \pm 0.48$ & $0.03^{*}$ \\
\hline $\begin{array}{l}\text { hs-CRP: High sensitivity C-reactive protein, CR: Cardiac } \\
\text { rehabilitation } \\
\text { *p }<0.05\end{array}$ & & \\
\hline
\end{tabular}

Table 3. Comparison of HbAlc Levels between the CR Group and Control Group 4 Months after CR Program Completion

\begin{tabular}{lccc}
\hline & $\begin{array}{c}\text { Exercise } \\
\text { group } \\
(\mathbf{n}=69)\end{array}$ & $\begin{array}{c}\text { Control } \\
\text { group } \\
(\mathbf{n}=72)\end{array}$ & p-value \\
\hline Uncontrolled DM & $2(3 \%)$ & $4(6 \%)$ & 0.68
\end{tabular}

(HbAlc $>6)$

HbAlc: Hemoglobin Alc, CR: Cardiac rehabilitation, DM: Diabetes mellitus 
(3\%) and 4 underwent revascularization surgery (6\%), 1 patient died (1.4\%) after the recurrence. The control group included 2 patients who underwent process monitoring after hospitalization (3\%), 7 who underwent coronary angiography (10\%), 7 who underwent revascularization surgery $(10 \%)$, and 1 death $(>1 \%)$.

\section{Kaplan-Meier curve of disease-free days and disease-} free rate between the exercise group and the control group

Compared with the control group (316 \pm 99.96 days), the exercise group had a noticeably larger number of disease-free days (354 \pm 38.34 days) during a period of one year after the initial stages of AMI $(\mathrm{p}<0.05$, Table 4$)$. In an identity test of the survival curve in the two groups, the recurrence rate showed a more significant reduction (14\%) in the exercise group than in the control group ( $\mathrm{p}<$ 0.05, Fig. 2). As a result, participation in the CR program resulted in extension of the number of disease-free days for AMI patients after the occurrence of disease.

\section{DISCUSSION}

Endothelial injury and atheromatous plaque rupture are inflammatory conditions caused by smoking and hyperglycemia and are involved in the atherosclerotic process. ${ }^{12-15}$ As the atherosclerotic process develops, inflammation caused by macrophagic transformation and migration, oxidation, and thrombosis occurs, and blood inflammatory protein, which takes part in inflammation, is increased accordingly. The inflammatory marker hsCRP is generally regarded as the most sensitive for future cardiovascular risk. ${ }^{6}$ This study demonstrated a marked reduction of hs-CRP in the exercise group patients who participated in the $\mathrm{CR}$ program.

Management of intensive risk factors, including exercise training in patients with coronary artery disease, is known to elicit significant recovery of atherosclerosis and coronary artery obstructive disease and reduction of recurrence rate. ${ }^{16}$ In particular, the exercise-induced CR program for patients with coronary artery disease is known to increase the survival rate and is efficient for use in risk factors management of coronary artery diseases. ${ }^{12}$ Patients who participated in the CR program and who had had PCI or CABG after AMI have been reported to result in enhanced management of risk factors and
Table 4. Cerebrovascular Events during a 1-year Period after the First AMI

\begin{tabular}{lccc}
\hline & $\begin{array}{c}\text { Exercise } \\
\text { group } \\
(\mathbf{n}=69)\end{array}$ & $\begin{array}{c}\text { Control } \\
\text { group } \\
(\mathbf{n}=72)\end{array}$ & p-value \\
\hline Disease free days & $354 \pm 38.34$ & $316 \pm 99.96$ & $0.003^{*}$ \\
Recurrence & $7(10 \%)$ & $17(24 \%)$ & $0.033^{*}$ \\
Need revascularization & $4(6 \%)$ & $7(10 \%)$ & 0.533 \\
Positive CAG & $2(3 \%)$ & $7(10 \%)$ & 0.166 \\
Need hospitalization & $0(0 \%)$ & $2(3 \%)$ & 0.497 \\
Death & $1(1.4 \%)$ & $1(>1 \%)$ & 0.953 \\
\hline
\end{tabular}

AMI: Acute myocardial infarction, CAG: Coronary angiography

${ }^{*} \mathrm{p}<0.05$

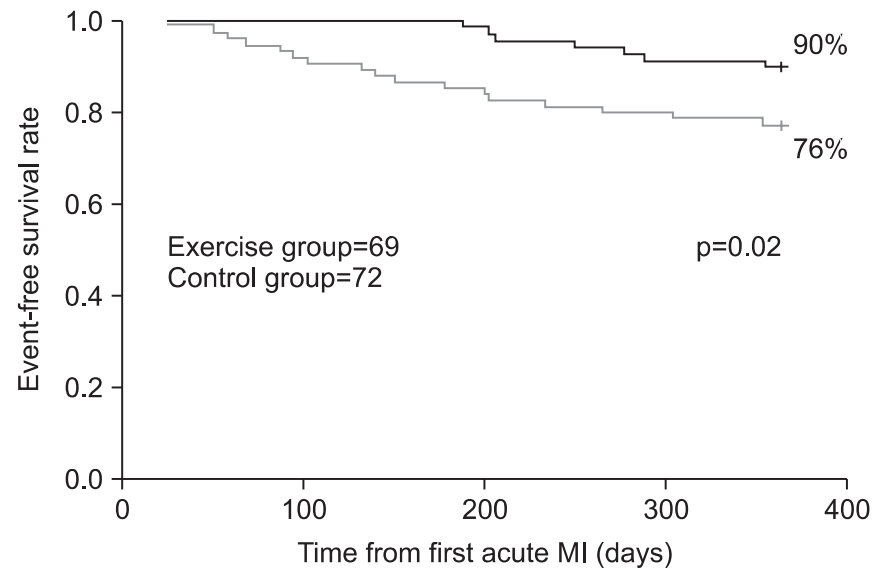

Fig. 2. Kaplan Meier event-free survival curve during the first year after acute myocardial infarction.

extended disease-free days. ${ }^{9,10}$ It is also known to reduce the mortality rate caused by cardiovascular and other diseases by approximately $20 \%{ }^{2,3}$

Results from this study showed that the recurrence rate for patients in the exercise group who participated in the CR program was reduced by about $14 \%$ compared to the control group. This result is somewhat different from the $18-20 \%$ reduction reported elsewhere. ${ }^{2,3,11}$ It can be attributed to differences of race, severity of disease, CR treatment period in the hospital, and compliance with the continuous self-exercise program in the community. Hammill reported that extension of the CR program up to 36 weeks resulted in a remarkable reduction of the mortality rate and rehospitalization rate in patients with coronary artery disease who received CABG by Medicare, the medical insurance system for the elderly and people 
with disability in the US. ${ }^{11}$

In this study, the exercise group showed a greater reduction (14\%) in recurrence rate and 38 more diseasefree days than the control group during the one-year monitoring period after strict risk factors management and 6-8 weeks of monitoring in the hospital, followed by self-exercise in the community after the initial occurrence of AMI in their lives. Taylor et al. ${ }^{2}$ reported reduction of the total mortality rate $(20 \%)$, cardiovascular disease mortality rate $(26 \%)$, total cholesterol level, triglyceride level, systolic blood pressure, and self-reported smoking rate in the exercise group; however, no distinctive differences in nonfatal re-infarction, revascularization rate, high density and low density lipoprotein cholesterol, and diastolic pressure were observed between the exercise group and the control group. Moreover, although O'Connor et al. ${ }^{3}$ reported greater reduction of total mortality rate $(20 \%)$, cardiovascular disease mortality rate $(22 \%)$, and fatal re-infarction (25\%) compared to the control group, during the 3 -year monitoring period, no significant difference was found in nonfatal re-infarction between the two groups.

The limitation in this study is that the exercise group and the control group were not chosen randomly and that a monitoring period of one year was too short for sufficient progress monitoring. Also, 1 death in each group during a period of one year was not supportive for comparison of the mortality rate between them.

Nevertheless, this study is important because it is the first to compare the recurrence rate and the mortality rate between patients in the exercise group, who participated in the CR program, and those in the control group, who did not, throughout a one-year period of monitoring of Korean patients. Further studies for comparison of the recurrence rate and the mortality rate on a continuous monitoring basis will be required.

\section{CONCLUSION}

The exercise group showed a greater reduction (14\%) of the recurrence rate and 38 more disease-free days than the control group during the one-year monitoring period after strict risk factors management and 6-8 weeks of monitoring in the hospital, followed by self-exercise in the community after the initial occurrence of AMI in their lives. hs-CRP of the exercise group at around 4 months after occurrence of the disease was reduced by $50 \%$ of that of the control group.

\section{REFERENCES}

1. Korea National Statistical Office. Annual report on the cause of death statistics 2008. Korea National Statistical Office 2008; 1: 7-14

2. Taylor RS, Brown A, Ebrahim S, Jolliffe J, Noorani H, Rees K, Skidmore B, Stone JA, Thompson DR, Oldridge N. Exercise-based rehabilitation for patients with coronary heart disease: systematic review and meta-analysis of randomized controlled trials. Am J Med 2004; 116: 682-692

3. O'Connor GT, Buring JE, Yusuf S, Goldhaber SZ, Olmstead EM, Paffenbarger RS Jr, Hennekens CH. An overview of randomized trials of rehabilitation with exercise after myocardial infarction. Circulation 1989; 80: 234-244

4. Witt BJ, Jacobsen SJ, Weston SA, Killian JM, Meverden RA, Allison TG, Reeder GS, Roger VL. Cardiac rehabilitation after myocardial infarction in the community. J Am Coll Cardiol 2004; 44: 988-996

5. Niebauer J, Hambrecht R, Velich T, Hauer K, Marburger C, Kalberer B, Weiss C, von Hodenberg E, Schlierf G, Schuler G, et al. Attenuated progression of coronary artery disease after 6 years of multifactorial risk intervention: role of physical exercise. Circulation 1997; 96: 2534-2541

6. King DE, Mainous AG 3rd, Taylor ML. Clinical use of C-reactive protein for cardiovascular disease. South Med J 2004; 97: 985-988

7. Pearson TA, Mensah GA, Alexander RW, Anderson JL, Cannon RO 3rd, Criqui M, Fadl YY, Fortmann SP, Hong Y, Myers GL, et al. Markers of inflammation and cardiovascular disease: application to clinical and public health practice: a statement for healthcare professionals from the Centers for Disease Control and Prevention and the American Heart Association. Circulation 2003; 107: 499-511

8. Rosenson RS, Koenig W. Utility of inflammatory markers in the management of coronary artery disease. Am J Cardiol 2003; 92: 10-18

9. Anderson JL, Adams CD, Antman EM, Bridges CR, Califf RM, Casey DE, Chavey WE 2nd, Fesmire FM, Hochman JS, Levin TN, et al. ACC/AHA 2007 
guidelines for the management of patients with unstable angina/non ST-elevation myocardial infarction: a report of the American College of Cardiology/ American Heart Association Task Force on Practice Guidelines (Writing Committee to Revise the 2002 Guidelines for the Management of Patients With Unstable Angina/Non ST-Elevation Myocardial Infarction): developed in collaboration with the American College of Emergency Physicians, the Society for Cardiovascular Angiography and Interventions, and the Society of Thoracic Surgeons: endorsed by the American Association of Cardiovascular and Pulmonary Rehabilitation and the Society for Academic Emergency Medicine. Circulation 2007; 116: e148-304

10. Antman EM, Anbe DT, Armstrong PW, Bates ER, Green LA, Hand M, Hochman JS, Krumholz HM, Kushner FG, Lamas GA, et al. ACC/AHA guidelines for the management of patients with ST-elevation myocardial infarction--executive summary. A report of the American College of Cardiology/American Heart Association Task Force on Practice Guidelines (Writing Committee to revise the 1999 guidelines for the management of patients with acute myocardial infarction). J Am Coll Cardiol 2004; 44: 671-719

11. Hammill BG, Curtis LH, Schulman KA, Whellan DJ. Relationship between cardiac rehabilitation and longterm risks of death and myocardial infarction among elderly Medicare beneficiaries. Circulation 2010; 121: 63-70

12. Ross R. Atherosclerosis--an inflammatory disease. N Engl J Med 1999; 340: 115-126

13. Bazzano LA, He J, Muntner P, Vupputuri S, Whelton PK. Relationship between cigarette smoking and novel risk factors for cardiovascular disease in the United States. Ann Intern Med 2003; 138: 891-897

14. Plutzky J. Inflammatory pathways in atherosclerosis and acute coronary syndromes. Am J Cardiol 2001; 88: K10-15

15. King DE, Mainous AG 3rd, Buchanan TA, Pearson WS. C-reactive protein and glycemic control in adults with diabetes. Diabetes Care 2003; 26: 1535-1539

16. Ornish D, Scherwitz LW, Billings JH, Brown SE, Gould KL, Merritt TA, Sparler S, Armstrong WT, Ports TA, Kirkeeide RL, et al. Intensive lifestyle changes for reversal of coronary heart disease. JAMA 1998; 280: 2001-2007 